\title{
A 2-Hour Diabetes Self-Management Education Program for Patients With Low Socioeconomic Status Improves Short-Term Glycemic Control
}

\author{
Michael G. Jakoby IV \\ Melissa Schleder \\ Vickie Luff \\ Cynthia Yergler \\ Albert Botchway \\ Cheryl Burns
}

Follow this and additional works at: https://aah.org/jpcrr

Part of the Dietetics and Clinical Nutrition Commons, Endocrine System Diseases Commons, Endocrinology, Diabetes, and Metabolism Commons, Health and Medical Administration Commons, Health Services Research Commons, Nursing Commons, Primary Care Commons, and the Public Health Education and Promotion Commons

\section{Recommended Citation}

Jakoby MG 4th, Schleder M, Luff V, Yergler C, Botchway A, Burns C. A 2-hour diabetes self-management education program for patients with low socioeconomic status improves short-term glycemic control. J Patient Cent Res Rev. 2020;7:275-81. doi: 10.17294/2330-0698.1745

Published quarterly by Midwest-based health system Advocate Aurora Health and indexed in PubMed Central, the Journal of Patient-Centered Research and Reviews (JPCRR) is an open access, peer-reviewed medical journal focused on disseminating scholarly works devoted to improving patient-centered care practices, health outcomes, and the patient experience. 


\title{
A 2-Hour Diabetes Self-Management Education Program for Patients With Low Socioeconomic Status Improves Short-Term Glycemic Control
}

\author{
Michael G. Jakoby IV, MD/MA, ${ }^{1}$ Melissa Schleder, RD/CDE, ${ }^{2}$ Vickie Luff, RN, MS,${ }^{3}$ Cynthia Yergler, \\ $\mathrm{RD} / \mathrm{CDE},{ }^{2}$ Albert Botchway, PhD, ${ }^{4}$ Cheryl Burns, RD/CDE ${ }^{2}$ \\ ${ }^{1}$ Division of Endocrinology, SIU School of Medicine, Springfield, IL; ${ }^{2}$ Diabetes Education, SIU School of Medicine, \\ Springfield, IL; ${ }^{3}$ Central Counties Health Center, Springfield, IL; ${ }^{4}$ Research, SIU School of Medicine, Springfield, IL
}

\begin{abstract}
Diabetes self-management education (DSME) improves glycemic control, but patients with low socioeconomic status face institutional and personal barriers to receiving DSME. A retrospective single cohort study of a 2-hour group DSME program prioritizing accessibility and completion of a tightly focused curriculum was performed to determine if glycemic control improved and whether a longer, more comprehensive, prospective evaluation of the program is indicated. All patients who participated in the program from September 2017 to December 2018 were included in the analysis. The primary study endpoint was change in hemoglobin $\mathrm{A} 1 \mathrm{c}(\mathrm{HbA1c})$ from baseline. A total of 58 out of 94 patients $(61.7 \%)$ had paired measurements of $\mathrm{HbA} 1 \mathrm{c}$. Mean HbA1c improved from $9.8 \% \pm 2.2 \%(83.5 \pm 24.2$ $\mathrm{mmol} / \mathrm{mol})$ to $8.3 \% \pm 2.0 \%(67.7 \pm 22.0 \mathrm{mmol} / \mathrm{mol})$ at a median of 4 months after participation in the program $(\mathrm{P}<0.001)$. The proportion of patients with any improvement in $\mathrm{HbA} 1 \mathrm{c}$ was $75.9 \%$ (44 of 58 ; $\mathrm{P}=0.003$ ), and $65.5 \%$ of patients (38 of $58 ; \mathrm{P}=0.066$ ) had an improvement in $\mathrm{HbA} 1 \mathrm{c}$ of $\geq 0.5 \%$. These results demonstrate the benefit of highly targeted DSME for low-income patients and justify a longerterm and prospective evaluation of the program. (J Patient Cent Res Rev. 2020;7:275-281.)
\end{abstract}

Keywords diabetes education; low socioeconomic status; type 2 diabetes mellitus; glycemic control

$\mathrm{T}$ here is a strong association between diabetes prevalence and socioeconomic status (SES). In the 2016 and 2017 National Health Interview Surveys, the prevalence of type 2 diabetes in the lowest quartile of income $(15.2 \%)$ was more than twice the prevalence in the highest income quartile $(7.1 \%) .{ }^{1}$ Low SES is also associated with worsening glycemic control due to poor self-care practices and suboptimal diet from food insecurity. ${ }^{2}$

Diabetes self-management education (DSME) improves glycemic control and is recommended by the American Diabetes Association (ADA) and

Correspondence: Michael G. Jakoby, MD/MA,

SIU School of Medicine, 701 N. First St., Suite D417,

Springfield, IL 62702 (mjakoby@siumed.edu)
American Association of Clinical Endocrinologists for all patients with diabetes. ${ }^{3-8}$ However, DSME is frequently unavailable or inaccessible for patients with low SES, and little has been published regarding DSME specifically for low-income diabetes patients. ${ }^{9}$ A DSME program for low-income and minority patients at the University of Miami was encouraging, with a $0.8 \%$ improvement in hemoglobin A1c (HbA1c) from baseline and $40 \%$ relative increase in the proportion of patients with HbAlc level of $<7 \%$ among participants completing the 4-week, 4-class, 12-hour program. ${ }^{10}$

The Southern Illinois University (SIU) Division of Endocrinology has partnered with Central Counties Health Center (CCHC) of Springfield, Illinois, a Federally Qualified Health Center, to provide on-site DSME free of charge for Medicaid and uninsured patients. Though research shows the largest 
improvements in glycemic control from programs with more than 10 hours of DSME contact time, certified diabetes educators from SIU created a 2-hour group DSME program at the request of $\mathrm{CCHC}$ administrative leadership, health care providers, and patients to prioritize accessibility and patient participation in a complete DSME curriculum. ${ }^{3}$ This study evaluates the effect of a short, single-session group DSME program on glycemic control in a low-SES population with type 2 diabetes mellitus.

\section{METHODS}

A retrospective cohort study approved by the Springfield Committee for Research Involving Human Subjects was performed. CCHC patients with type 2 diabetes mellitus who participated in the SIU on-site group DSME program from September 2017 through December 2018 and who had hemoglobin A1c (HbA1c) checked within 3 months before participation formed the study population. Referrals to the program were made entirely at the discretion of $\mathrm{CCHC}$ health care providers, and all patients were Medicaid beneficiaries, Medicare beneficiaries, or uninsured (Table 1).

Study-eligible patients participated in a free onetime, 2-hour group DSME session covering topics in the ADA national standards for DSME, but with adjustments for low health and numerical literacy modeled on the Living With Diabetes guidebook (Table 2 and Figure 1). ${ }^{7,11,12}$ The SIU Division of Endocrinology has an ADA-recognized DSME program, and the group DSME program for CCHC was developed and led by SIU Division of Endocrinology certified diabetes educators. Sessions were held monthly and limited to a maximum of 15 participants. There was no minimum enrollment. All patients were first-time DSME recipients. There were no significant changes in clinic operating procedures for patients with diabetes during the 15-month period for data analysis.

Age, gender, mode of diabetes management, and baseline HbA1c were recorded for all participants. HbA1c measured in a 3-to-6-month interval after participation was also recorded when available. All $\mathrm{HbA1c}$ measurements were obtained at point of care using a device in conformance with the National
Table 1. Income and Insurance Status of $\mathrm{CCHC}$ Diabetes Education Patients ( $\mathrm{N}=94)$

\begin{tabular}{lc}
\hline Parameter & $\begin{array}{c}\text { Proportion of } \\
\text { patients }\end{array}$ \\
\hline Income & \\
$100 \%$ of poverty level or below & $73 \%$ \\
$101 \%-150 \%$ of poverty level & $15 \%$ \\
$151 \%-199 \%$ of poverty level & $6 \%$ \\
$\geq 200 \%$ of poverty level & $6 \%$ \\
Insurance* & \\
Illinois Medicaid only & $78 \%$ \\
Medicare only & $4 \%$ \\
Illinois Medicaid and Medicare & $4 \%$ \\
Uninsured & $13 \%$ \\
\hline
\end{tabular}

${ }^{*}$ Does not add up to $100 \%$ due to rounding.

CCHC, Central Counties Health Center (Springfield, IL)

Table 2. Topics and Time Allocation in Diabetes Education Sessions

\begin{tabular}{ll}
\hline Component & Time \\
\hline Sign in and self-assessment & 15 minutes \\
Education topics: & 90 minutes \\
$>$ What is diabetes? & \\
$>$ Health problems when a person & \\
& has diabetes \\
$>$ & Medication changes in diabetes \\
& treatment with time \\
$>$ & Lowering risk of health problems \\
& when you have diabetes \\
$>$ Physical activity & \\
$>$ Meal planning & \\
$>$ & Foot care basics \\
Goal setting and adjourn &
\end{tabular}

Glycohemoglobin Standardization Program (DCA Vantage ${ }^{\circledR}$ Analyzer, Siemens Medical Solutions, Inc.); the coefficient of variance for low and high $\mathrm{HbA} 1 \mathrm{c}$ standards was $1.8 \%$ and $3.7 \%$, respectively. ${ }^{13}$

The primary study endpoint was change in paired HbAlc measurements from baseline. Secondary endpoints were proportions of patients with any improvement in $\mathrm{HbAlc}$ and $\mathrm{HbAlc}$ improvement of 
Each of the food portions listed $=1$ carbohydrate choice $=15$ grams carb

\begin{tabular}{|c|c|c|c|}
\hline Starches & Starchy Vegetables \& Beans & Milk \& Yogurt & Sweets, Snacks \& Drinks \\
\hline $\begin{array}{c}5-7 \text { crackers } \\
20 \text { oyster crackers } \\
2 \text { rice cakes } \\
1 \text { slice of bread ( } 1 \text { oz) } \\
1 \text { small tortilla ( } 6 \text { inch) } \\
1 / 2 \text { hamburger/hotdog bun } \\
2 \text {-inch square cornbread } \\
1 / 4 \text { bagel } \\
1 / 2 \text { English muffin } \\
1 / 2 \text { pita } \\
1 \text { small dinner roll } \\
1 \text { toaster waffle } \\
1 \text { small pancake ( } 4 \text { inch) } \\
1 / 2 \text { cup cooked noodles } \\
1 / 3 \text { cup cooked rice } \\
1 / 3 \text { cup cooked polenta } \\
1 / 2 \text { cup cooked grits or } \\
\text { oatmeal } \\
3 / 4 \text { cup of MANY cold } \\
\text { cereals } \\
1 / 4 \text { cup granola } \\
3 \text { cups of plain popcorn }\end{array}$ & $\begin{array}{c}\text { Combination Foods } \\
1 \text { cup soup } 1 \text { cup beef stew } \\
6 \text { chicken nuggets } \\
1 / 4 \text { cup of potato or macaroni salad } \\
1 / 3 \text { cup baked beans } \\
1-10^{\text {th }} 14 \text { in. thin crust pizza } \\
1 / 4 \text { of } 12 \text { in. ( } 5 \text { oz) thin crust pizza } \\
1 / 2 \text { cup casserole (lasagna, tuna noodle) } \\
1 / 2 \text { fried fish fillet pieces } \\
1 / 2 \text { cup chili with beans } \\
1 / 2 \text { cup macaroni \& cheese }\end{array}$ & $\begin{array}{c}1 \text { cup non-fat, low-fat, whole milk } \\
1 / 2 \text { cup evaporated milk } \\
1 \text { cup buttermilk } \\
1 \text { cup goat's milk } \\
1 / 2 \text { cup chocolate milk } \\
1 \text { cup of soymilk } \\
1 \text { cup rice milk } \\
1 / 2 \text { cup eggnog } \\
3 / 4 \text { cup yogurt } \\
6 \text { oz. artificially sweetened yogurt } \\
2 / 3 \text { cup yogurt with fruit } \\
3 \text { oz. flavored smoothie } \\
\text { Fruit } \\
1 \text { cup Fresh Fruit } \\
1 \text { small piece of fruit ( } 3 \text { oz.) } \\
15 \text { grapes } \\
1 / 2 \text { cup canned or frozen fruit } \\
1 / 4 \text { cup of dried fruit } \\
1 / 2 \text { cup of } 100 \% \text { fruit juice } \\
1 / 2 \text { cup of applesauce }\end{array}$ & $\begin{array}{c}2 \text { Oreos } \\
5 \text { vanilla wafers } \\
2 \text { small chocolate chip cookies } \\
3 \text { small gingersnaps } \\
5 \text { Hershey's kisses } \\
3 \text { Snickers miniature candy pieces } \\
3 \text { peppermint candies } \\
3 \text { pieces hard candy } \\
1 / 2 \text { cup regular Jell-O } \\
1 / 2 \text { cup sugar free pudding } \\
1 \frac{1 / 4 \text {-inch square brownie (unfrosted) }}{2 \text { - inch square cake (unfrosted) }} \\
1 / 2 \text { plain cake doughnut } \\
1 / 2 \text {-inch slice banana nut bread } \\
1 \text { tbsp. jelly } 1 \text { tbsp. honey } \\
1 \text { tbsp. sugar } \quad 1 \text { tbsp. agave nectar } \\
1 \text { tbsp. chocolate/caramel syrup } \\
1 / 2 \text { cup regular ice cream } \\
1 / 4 \text { cup sherbet or sorbet } \\
10 \text { potato chips } \\
1 \text { oz. trail mix } \\
10 \text { tortilla chips } \\
3 / 4 \text { oz. pretzels }\end{array}$ \\
\hline
\end{tabular}

Figure 1. Representative page from the handout provided to class participants.

$\geq 0.5 \%$, which is considered clinically significant. ${ }^{14}$ Continuous variables are expressed as means \pm standard deviations and categorical variables as proportions unless indicated otherwise. Student's $t$-test and Fischer's exact test were used to compare continuous and categorical variables, respectively. Logistic regression was performed to identify factors predictive of an improvement in $\mathrm{HbA} 1 \mathrm{c}$ of $\geq 0.5 \%$. A sample size calculation indicated that 25 patients with paired $\mathrm{HbA1c}$ values were required to detect a $0.7 \%$ improvement in $\mathrm{HbA} 1 \mathrm{c}$ at $\alpha$ of 0.05 and $\beta$ of 0.08. Prism 5 for Windows (GraphPad Software) and SPSS Statistics 19.0 (IBM Corporation) were used for statistical analyses. P-values less than 0.05 were considered statistically significant.

\section{RESULTS}

Clinical parameters at time of participation in the group DSME program are summarized in Table 3. A total of 94 patients participated in the program, and $58(61.7 \%)$ had HbA1c rechecked 3-6 months after DSME. Patients with and without paired HbA1c measurements were very similar across all clinical parameters. Mean baseline $\mathrm{HbAlc}$ for the entire patient population was $9.7 \% \pm 2.3 \%(82.1 \pm 25.2$ $\mathrm{mmol} / \mathrm{mol}$ ), and $43.6 \%$ of patients were treated with either insulin alone or in combination with noninsulin therapeutics.

Comparison of paired $\mathrm{HbAlc}$ measurements before and after participation in the DSME program is 
Table 3. Key Clinical Parameters

\begin{tabular}{|c|c|c|c|}
\hline Parameter & $\begin{array}{l}\text { Paired HbA1c } \\
\qquad(n=58)\end{array}$ & $\begin{array}{l}\text { No paired HbA1c } \\
(n=36)\end{array}$ & $P$ \\
\hline Mean age \pm SD & $56 \pm 9$ years & $55 \pm 11$ years & 0.733 \\
\hline Female gender & $55 \%$ & $60 \%$ & 0.672 \\
\hline Preclass mean $\mathrm{HbA} 1 \mathrm{c} \pm \mathrm{SD}$ & $\begin{array}{c}9.8 \% \pm 2.2 \% \\
(83.5 \pm 24.2 \mathrm{mmol} / \mathrm{mol})\end{array}$ & $\begin{array}{c}9.4 \% \pm 2.5 \% \\
(79.6 \pm 27.0 \mathrm{mmol} / \mathrm{mol})\end{array}$ & 0.486 \\
\hline \multicolumn{4}{|l|}{ Mode of treatment } \\
\hline Diet only & $3.4 \%$ & $5.6 \%$ & 0.636 \\
\hline Oral medications & $36.2 \%$ & $33.3 \%$ & 0.827 \\
\hline Oral meds + GLP-1 agonist & $12.1 \%$ & $2.9 \%$ & 0.148 \\
\hline Oral meds + insulin & $27.6 \%$ & $27.8 \%$ & 1.000 \\
\hline Insulin only & $13.8 \%$ & $19.4 \%$ & 0.565 \\
\hline Not recorded & $6.9 \%$ & $11.1 \%$ & 0.477 \\
\hline
\end{tabular}

HbA1c, hemoglobin A1c; SD, standard deviation.

\section{Glycemic control after class}

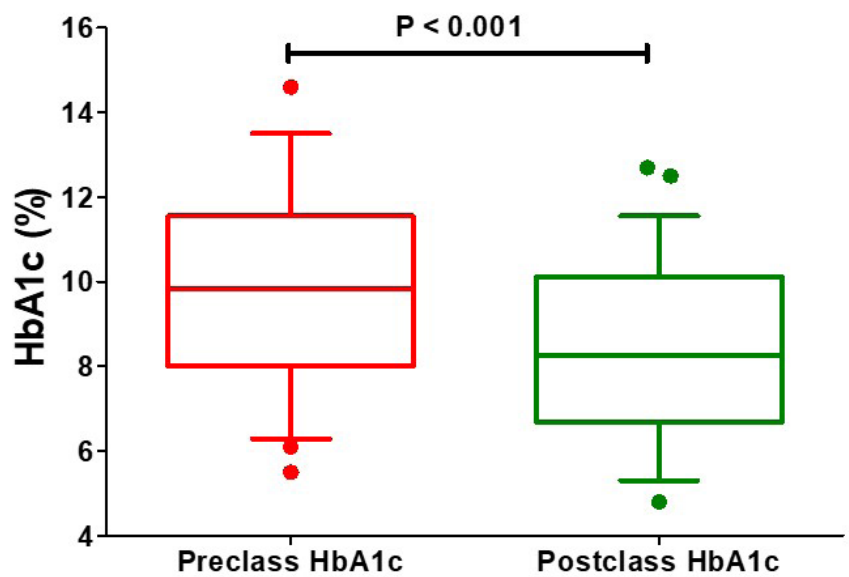

Figure 2. Whisker plots of hemoglobin A1c (HbA1c) before and after participation in class. Lines are medians, boxes define interquartile ranges, and error bars are $95 \%$ confidence intervals. Individual outliers are plotted as dots. Median time to postclass HbA1c was 4 months (range: 3-6).

presented in Figure 2. Median time to the next $\mathrm{HbA1c}$ measurement after DSME was 4 months (range: 3-6). Mean HbAlc improved from 9.8\% $\pm 2.2 \%(83.5 \pm$ $24.2 \mathrm{mmol} / \mathrm{mol})$ before DSME to $8.3 \% \pm 2.0 \%(67.7$ $\pm 22.0 \mathrm{mmol} / \mathrm{mol})$ after participation $(\mathrm{P}<0.001)$. The proportion of patients with any improvement in $\mathrm{HbA} 1 \mathrm{c}$ from baseline as well as those with improvement in $\mathrm{HbA} 1 \mathrm{c}$ of $\geq 0.5 \%$ is presented in Table 4 . A total of 44 patients $(75.9 \% ; \mathrm{P}=0.003)$ had an improvement from baseline, while 38 patients $(65.5 \%$; $\mathrm{P}=0.066)$ showed an improvement of $\geq 0.5 \%$.

Logistic regression analysis was performed to determine if any clinical parameters were predictive of $\mathrm{a} \geq 0.5 \%$ improvement in $\mathrm{HbA} 1 \mathrm{c}$ from baseline. Results are presented in Table 5. Baseline HbA1c of $\geq 10 \%$ was the only parameter predictive of $a \geq 0.5 \%$ improvement in $\mathrm{HbA} 1 \mathrm{c}$ (odds ratio: $10.23,95 \% \mathrm{CI}$ : 2.48-42.26; $\mathrm{P}=0.001$ ).

\section{DISCUSSION}

There is strong evidence that DSME improves glycemic control. In a systematic review of 118 studies, mean improvements in $\mathrm{HbA1c}$ from baseline compared to controls for individual and group diabetes education program participants were $0.78 \%$ and $0.62 \%$, respectively. ${ }^{6}$ Unfortunately, only about half of patients with diabetes receive DSME, and Medicaid and uninsured patients are $20 \%-30 \%$ less likely to receive DSME than patients with commercial insurance. ${ }^{15,16}$ Low-income patients often receive health care in clinics where the availability and quality of DSME programs are limited and have personal barriers to participation such as lack of transportation, inability to take time off work, requirements for child care, and 
Table 4. Proportion of Patients With Improved Hemoglobin A1c $(n=58)$

\begin{tabular}{lcccc}
\hline Parameter & Yes & No & $\%$ & $P$ \\
\hline Any improvement in hemoglobin A1c & 44 & 14 & 75.9 & 0.003 \\
Hemoglobin A1c improved by $\geq 0.5 \%$ & 38 & 20 & 65.5 & 0.066 \\
Hemoglobin A1c improved by $\geq 1.0 \%$ & 30 & 28 & 51.7 & -- \\
Hemoglobin A1c improved by $\geq 1.5 \%$ & 23 & 35 & 39.7 & -- \\
\hline
\end{tabular}

Table 5. Predictors of Hemoglobin A1c Improvement of $\geq 0.5 \%$ ( $n=58)$ by Logistic Regression

\begin{tabular}{lcc}
\hline Parameter & Odds ratio $(95 \% \mathrm{Cl})$ & $\boldsymbol{P}$ \\
\hline Preclass hemoglobin A1c of $\geq 10 \%(\mathrm{n}=28)$ & $10.23(2.48-42.26)$ & 0.001 \\
Age in years & $0.88(0.24-3.24)$ & 0.844 \\
Gender (reference: female) & $1.04(0.29-3.71)$ & 0.958 \\
Mode of treatment (reference: diet only) & & \\
$\quad$ Noninsulin therapies only & $0.24(0.05-1.21)$ & 0.085 \\
$\quad$ Insulin (with or without oral medications) & $1.60(0.41-6.31)$ & 0.499 \\
\hline
\end{tabular}

unaffordable fees or copayments. ${ }^{9}$ The attrition rate for multisession DSME programs is generally high, and fewer than half of participants fully completed the University of Miami multisession DSME program for low-income patients. ${ }^{3,10}$ Since completion of DSME programs is predictive of improved glycemic control, it is reasonable to explore the effectiveness of a highly focused and short DSME program. ${ }^{3}$

The results of this study indicate that a 2-hour, singlesession group DSME program for uninsured and underinsured low-income patients can significantly improve glycemic control in the first 3-6 months after participation. Mean improvement in $\mathrm{HbAlc}$ from baseline for participants with paired measurements before and after DSME was highly significant at $1.5 \%$ $(\mathrm{P}<0.001)$ and compares favorably to the improvement in glycemic control in meta-analyses of group DSME programs $(0.46 \%$ and $0.62 \%)$, for low-income patients completing the University of Miami multisession DSME program $(0.82 \%)$, and a randomized controlled trial of Federally Qualified Health Center patients receiving standard DSME (1.4\%) or DSME augmented with telephonic support $(1.7 \%)^{6,10,17,18}$ More than $75 \%$ of $\mathrm{CCHC} / \mathrm{SIU}$ patients had an improvement in
HbA1c from baseline, and approximately two-thirds had an improvement in HbAlc that was $\geq 0.5 \%$. Although the proportion of patients with improvement in $\mathrm{HbA} 1 \mathrm{c}$ of $\geq 0.5 \%$ was not quite statistically significant, the majority of patients completing the program had a clinically meaningful improvement in glycemic control. ${ }^{14}$

The logistic regression analysis found that baseline $\mathrm{HbA} 1 \mathrm{c}$ of $\geq 10 \%$ was the only patient factor predictive of $\mathrm{a} \geq 0.5 \%$ improvement in $\mathrm{HbA} 1 \mathrm{c}$. However, the finding that very poor baseline glycemic control is predictive of significant glycemic improvement is unexpected. In Project Dulce, a program in San Diego County for lowincome and underserved patients with diabetes, high baseline HbA1c, along with duration of diabetes, lack of insurance, treatment with insulin or multiple oral diabetes medications, and high baseline cholesterol, was associated with continued poor glycemic control. ${ }^{19}$ Relatively few patient characteristics ( $\mathrm{HbA} 1 \mathrm{c}$ before class, age, gender, and mode of diabetes management) were assessed in this study, and it is possible a more comprehensive evaluation could identify additional factors that are also predictive of significant glycemic improvement. 
Our study has several strengths. First, all participants completed a common DSME program developed and presented by experienced registered dietitians/ certified diabetes educators in a university-based and ADA-recognized DSME program. Second, all HbA1c measurements for the study were obtained by a common point-of-care testing device in the clinic, allowing for accurate timing of measurements relative to participation in the DSME program and direct comparisons of results before and after class. Third, patients were managed by a relatively small panel of primary care providers at $\mathrm{CCHC}$ and could fill prescriptions for medications and devices (eg, glucose meters and strips) at the clinic, limiting variability of health care providers and inconsistent access to therapeutic agents as potential confounding factors. Finally, all patient documentation and laboratory results were in a single medical record that helped ensure completeness and fidelity of data collection.

Some study limitations need to be recognized. Measurement of HbA1c in the stipulated interval after participation in class was incomplete, and it is possible that results are skewed due to selection bias. However, there was no difference in baseline characteristics of program participants with or without paired $\mathrm{HbA} 1 \mathrm{c}$ measurements. Measurement of glycemic benefit is limited to 6 months from participation in class, with $\mathrm{HbA} 1 \mathrm{c}$ measured a median of 4 months after participation. It is possible that glycemic benefit wanes with time, and the durability of improved hyperglycemia after this single DSME session needs to be assessed in another study. Other potential clinical variables of interest, such as blood pressure, weight, and lipids, were not assessed. Also, there was no formal assessment of diabetes knowledge before and after sessions. Finally, a relatively small number of patient characteristics were recorded, limiting the ability to identify potential factors that predict significant benefit from this DSME program. However, the primary goal of this study was to determine if the impact of this new DSME program on glycemic control is significant and indicates that a longer, more comprehensive, and prospective evaluation is appropriate.

In summary, the 2-hour, single-session SIU/CCHC diabetes self-management education program significantly improved glycemic control as indicated by changes in paired $\mathrm{HbAlc}$ measurements before and 3-6 months after participation. Though the Patient Protection and Affordable Care Act of 2010 has extended health insurance to many adults with diabetes, there is still a large population of patients who remain uninsured or have insurance that does not cover the costs of DSME. If confirmed by a prospective and longer-term study, this program could serve as a model for DSME at other Federally Qualified Health Centers and community health centers that provide care to patients with significant barriers to participation in other DSME forums that are presented over multiple sessions and several hours of contact time.

\section{Patient-Friendly Recap}

- Diabetes self-management education is recommended for all patients with diabetes mellitus because it teaches them how to control their blood sugar.

- Low-income patients are less likely than those with private health insurance to benefit from multiple-session educational programs, due in part to barriers such as lack of transportation or child care.

- In testing a short (2-hour), single-session group diabetes education program, the authors found that blood sugar (hemoglobin A1c) levels of federally insured or uninsured patients improved $\sim 4$ months after participation.

- If confirmed by a prospective study with longer follow-up, this novel program could serve as a blueprint for effective diabetes education offered to low-income patients.

\section{Author Contributions}

Study design: Jakoby, Burns. Data acquisition or analysis: Jakoby, Luff, Botchway, Burns. Manuscript drafting: all authors. Critical revision: all authors.

\section{Conflicts of Interest}

None.

\section{References}

1. Xu G, Liu B, Sun Y, et al. Prevalence of diagnosed type 1 and type 2 diabetes among US adults in 2016 and 2017: population based study. BMJ. 2018;362:k1497. CrossRef 
2. Robbins JM, Vaccarino V, Zhang H, Kasl SV. Socioeconomic status and type 2 diabetes in African American and nonHispanic white women and men: evidence from the Third National Health and Nutrition Examination Survey. Am J Public Health. 2001;91:76-83. CrossRef

3. Norris SL, Lau J, Smith SJ, Schmid CH, Engelgau MM. Selfmanagement education for adults with type 2 diabetes: a metaanalysis of the effect on glycemic control. Diabetes Care. 2002;25:1159-71. CrossRef

4. Frosch DL, Uy V, Ochoa S, Mangione CM. Evaluation of a behavior support intervention for patients with poorly controlled diabetes. Arch Intern Med. 2011;171:2011-7. CrossRef

5. Cooke D, Bond R, Lawton J, et al. Structured type 1 diabetes education delivered within routine care: impact on glycemic control and diabetes-specific quality of life. Diabetes Care. 2013;36:270-2. CrossRef

6. Chrvala CA, Sherr D, Lipman RD. Diabetes self-management education for adults with type 2 diabetes mellitus: a systematic review of the effect on glycemic control. Patient Educ Couns. 2016;99:926-43. CrossRef

7. American Diabetes Association. 5. Lifestyle Management: Standards of Medical Care in Diabetes - 2019. Diabetes Care. 2019;42(Suppl 1):S46-60. CrossRef

8. Handelsman Y, Bloomgarden ZT, Grunberger G, et al. American Association of Clinical Endocrinologists and American College of Endocrinology - Clinical Practice Guidelines for Developing a Diabetes Comprehensive Care Plan - 2015. Endocr Pract. 2015;21 Suppl 1:1-87. CrossRef

9. Shaw K, Killeen M, Sullivan E, Bowman P. Disparities in diabetes self-management education for uninsured and underinsured adults. Diabetes Educ. 2011;37:813-9. CrossRef

10. Ryan JG, Jennings T, Vittoria I, Fedders M. Short and longterm outcomes form a multisession diabetes education program targeting low-income minority patients: a six-month follow up. Clin Ther. 2013;35:A43-53. CrossRef
11. American College of Physicians. Living with Diabetes: An Everyday Guide for You and Your Family. Philadelphia, PA: American College of Physicians Foundation, 2007.

12. Seligman HK, Wallace AS, DeWalt DA, et al. Facilitating behavior change with low-literacy patient education materials. Am J Health Behav. 2007;31 Suppl 1:S69-78. CrossRef

13. Lenters-Westra E, Slingerland RJ. Six of eight hemoglobin A1c point-of-care instruments do not meet the general accepted analytical performance criteria. Clin Chem. 2010;56:44-52. CrossRef

14. Stratton IM, Adler AI, Neil HA, et al. Association of glycaemia with macrovascular and microvascular complications of type 2 diabetes (UKPDS 35): prospective observational study. BMJ. 2000;321(7258):405-12. CrossRef

15. Nelson K, Chapko MK, Reiber G, Boyko EJ. The association between health insurance coverage and diabetes care: data from the 2000 Behavioral Risk Factor Surveillance System. Health Serv Res. 2005;40:361-72. CrossRef

16. Shaw K, Killeen M, Sullivan E, Bowman P. Disparities in diabetes self-management education for uninsured and underinsured adults. Diabetes Educ. 2011;37:813-9. CrossRef

17. Bluml BM, Kolb LE, Lipman R. Evaluating the impact of yearlong, augmented diabetes self-management support. Popul Health Manag. 2019;22:522-8. CrossRef

18. Steinsbekk A, Rygg LØ, Lisulo M, Rise MB, Fretheim A. Group based diabetes self-management education compared to routine treatment for people with type 2 diabetes mellitus. A systematic review with meta-analysis. BMC Health Serv Res. 2012:12:213. CrossRef

19. Benoit SR, Fleming R, Philis-Tsimikas A, Ji M. Predictors of glycemic control among patients with type 2 diabetes: a longitudinal study. BMC Public Health. 2005;5:36. CrossRef

(C) 2020 Aurora Health Care, Inc. 